\title{
Research Status and Prospects of Tribological Behaviors of Key Friction Pairs of Materials in Marine Equipment
}

\author{
Chengpeng WANG ${ }^{1,2}$, Shenghui WANG ${ }^{2 *}$, Haizeng WANG ${ }^{1}$, Guoling RUAN $^{2}$, \\ Yexiang XIAO ${ }^{3}$, Zuguang JIANG $^{4}$, Xiupeng LI $^{5}$
}

${ }^{1}$ College of Chemistry and Chemical Engineering, Ocean University of China, Qingdao 266003, China

${ }^{2}$ The Institute of Seawater Desalination \& Multipurpose Utilization, MNR, Tianjin 300192, China,

${ }^{3}$ State Key Laboratory of Hydroscience and Engineering \& Department of Thermal Engineering, Tsinghua University, Beijing 100084, China

${ }^{4}$ Zhejiang Woer Technology Co. LTD, Jiaxing 314306, China

${ }^{5}$ Shandong Shuanglun Co. LTD, Weihai 210004, China

crossref http://dx.doi.org/10.5755/j02.ms.22504

Received 15 January 2019; accepted 03 September 2019

\begin{abstract}
Marine environment provides a basic space for human survival and social sustainable development. The study of tribological problems and mechanism of marine engineering materials in the sea extreme environment has become one of key technologies to be developed urgently in the field of marine engineering. This review summarizes and analyzes the tribological research of key friction materials in marine environment, focuses on tribological properties of ceramic, polymer and metal, emphatically introduces the current situation and development trend of tribological research in marine environment, such as metal and metal pairs, ceramics and metal pairs, polymers and metal pairs, polymers and ceramic pairs, and aims to provide a tutorial reference for the selection and application of friction pairs of marine engineering equipment.

Keywords: marine, friction, tribology, ceramics, corrosion wear.
\end{abstract}

\section{INTRODUCTION}

The 21 st century is a new century for mankind to fully understand, exploit and protect the oceans. The ocean area accounts for about $70.8 \%$ of the earth's total area and is often considered to be the most corrosive natural environment. It as a highly complex medium contains almost every element of the periodic table and a wide variety of organisms. The development and breakthrough of marine engineering materials is the foundation and forerunner to realize marine science technology innovation and marine sustainable development. The study of tribological problems and failure mechanism of marine engineering materials in the sea extreme environment has become one of key technologies to be developed urgently in the field of marine engineering. The sea contains abundant resources. The exploitation and utilization of marine resources play a key role in the country development, and have become an important symbol of a country's comprehensive strength.

According to the relevant information, the common key friction materials in the seawater environment show different degrees of corrosion and friction wear, such as key friction parts of seawater piston pump, key components of ship power system and so on, due to the corrosive environment of seawater [1]. Seawater has low viscosity, poor lubrication and strong corrosion, and contains a lot of sediments and microorganisms, which have a great influence on the tribological properties of key

\footnotetext{
* Corresponding author. Tel.: +086-022-87898282.

E-mail address: wang_sh04@126.com (S.H. Wang)
}

friction materials of marine equipment under the seawater lubrication. In the complex and changeable marine environment, the way of self-matching of metallic materials makes the corrosion of materials very serious $[2,3]$. According to the statistics, the annual losses caused by corrosion damage accounts for about $3 \%$ of the world's gross national production, and the seawater corrosion accounts for about $33.3 \%$ of the total amount of corrosion [4]. Therefore, it is of great practical significance to develop marine composites as key friction pairs in key friction materials of marine engineering equipment under the special environment. The particularity and complexity of marine environment restrict the application of friction materials, put forward higher requirements for materials properties. The selection of key friction materials has become a key technical problem in the development of marine equipment technology. Moreover, it is complex that the tribological behavior of key friction pairs materials of marine equipment due to the corrosivity of marine extreme environment. The mechanism of friction and wear in harsh marine environment is the key problem restricting marine application and developing marine equipment.

This paper reviews the tribological properties of ceramic, polymer and metal under the condition of seawater lubrication, and focus on discussing the interaction of corrosion and wear of metallic materials under the seawater environment. The authors emphatically introduce the current situation and development trends of tribology research in the marine environment, such as the matching of PEEK and metal pairs, PEEK and ceramics, and looks forward to this field. It should be noted that the review tends to be qualitative rather than quantitative 
analysis because of the individuality and variability of existing wear and tear experiments.

\section{TRIBOLOGICAL BEHAVIOR OF MATERIALS}

With the further development of seawater desalination, it is also required that some key friction components of marine equipment can continue to work safely and stably under the extremely harsh condition. Hence, the higher requirements are put forward for the performance of key friction materials. However, some researches are still in a state of secrecy, and the tribology research of marine environment is still rare at home and abroad due to the high cost of friction test in high pressure seawater environment.

\subsection{Metallic materials}

The electrochemical corrosion of metallic materials put forward a severe test on the application of metallic materials in the seawater environment. It is very important to study the tribological behavior of metallic materials in seawater environment. The tribological studies of metallic materials under seawater is listed in Table 1.

Table 1. Tribological studies of metallic materials under seawater

\begin{tabular}{|l|l|}
\hline \multicolumn{1}{|c|}{ Authors } & \multicolumn{1}{c|}{ Materials } \\
\hline Chen et al. [3] & $\begin{array}{l}\text { TC4 alloy, Hastelloy C-276 alloy, Inconel 625 } \\
\text { alloy, Monel K500 alloy, 316 steel }\end{array}$ \\
\hline Wang et al. [5] & $\begin{array}{l}\text { 316 steel, Hastelloy C-276, Inconel 625, TC4 } \\
\text { alloy }\end{array}$ \\
\hline Zhang et al. [6] & Austenitic stainless steel \\
\hline Cui et al. [7] & $\mathrm{Cu}-6 \mathrm{Sn}-6 \mathrm{Zn-3Pb}$ alloy \\
\hline Zhu et al. [8] & $\mathrm{Ni3Al-Cr-Mo,} \mathrm{Ti-6Al-4V}$ \\
\hline Ren et al. [9] & $\mathrm{NiCr}$ alloy, stainless steel \\
\hline
\end{tabular}

As researched in above documents, the seawater environment has three effects on the tribological properties of metallic materials, including friction and wear, electrochemical corrosion, and interaction between corrosion and wear [2]. The interaction between wear and corrosion can be understood as the comprehensive effect of the destruction-repair of passivation film forming on metal wear surface. The continuous sliding between the contact surfaces during the friction process, and the formation of many microcracks in passivation film under the action of contact stress. Microcracks could continue to expand until the local rupture. The chlorine ions in the seawater will also make the passivation film more easily destroyed. The exposed metal surface is affected by the corrosion under seawater. The surface shear force will cause the plastic deformation of metal surface, making it more prone corrosion. The re-passivation process also aggravates corrosion, and the wear promotes corrosion. In addition, the seawater penetrates into the microcracks on the worn surfaces. The spread and proliferation of cracks accelerate during the friction process. The corroded surface is loose and porous, making it easier to increase the surface wear. The failure of passivation film reduces the contact area of friction pairs, increases the contact stress, resulting in a higher wear rate. The interaction between corrosion and wear is one of the key nonnegligible factors of affecting the tribological behavior of materials.

\subsection{Ceramic materials}

With the continuous research and development of ceramic materials, its high hardness, high temperature resistance, corrosion resistance and wear resistance, as well as excellent oxidation resistance and chemical stability, is widely used in corrosion-resistant wear friction components [10]. Hence, the application of ceramic materials expands in high-speed cutting tools, aerospace, engine key components, marine engineering equipment, petroleum machinery and other fields. The appearance of ceramic composites with excellent performances provides a new idea and direction for the selection of key friction materials of marine equipment in seawater desalination, and provides a strong support for the study of material tribological behavior in marine environment.

At present, most of the research on tribological properties of key friction pairs of ceramic materials is carried out under artificial seawater or $3.5 \% \mathrm{NaCl}$ simulated solution. This research on friction and wear in natural waters, especially in actual seawater, is relatively rare. The tribological studies on ceramic materials including $\mathrm{Si}_{3} \mathrm{~N}_{4}$ [11], SiC ceramics [12, 13], Sialon [13], $\mathrm{ZrO}_{2}$ [13], and $\mathrm{Al}_{2} \mathrm{O}_{3}$ [13] could be referred to those related documents. Due to the existence of salt ions in seawater, the tribological behavior of ceramic materials in seawater environment is obviously different from the counterpart in other aqueous solutions. It need to be further explored in the film forming mechanism of the friction surface of ceramic materials in seawater, as well as the interaction between seawater environment and friction behavior.

\subsection{Polymer materials}

Polymer materials have the advantages of small density, high specific strength, high elasticity, good chemical stability, strong corrosion resistance, and have a very important application prospect in marine equipment, such as seawater hydraulic transmission elements [14]. However, the water absorption of polymer materials will affect its physical and mechanical properties, leading to surface plasticizing, and deterioration of wear resistance. In addition, the suction swelling of polymer materials will also affect the mating of friction elements, reduce the accuracy of matching pairs $[2,10]$. The seawater corrosion could reduce the fracture toughness and ageing-resistant performance of polymer materials. Therefore, the tribological behavior of polymer materials in aqueous solution, especially in seawater environment, is obviously different from that under the condition of dry friction. In general, polymers exhibit excellent tribological properties in seawater environments, and the effects of waterabsorbing plasticizing, the corrosion effects of dual parts, and the lubrication of seawater are taken into account using polymers for key friction materials.

At present, the tribological research on polymer materials under seawater lubrication is still relatively rare, and lack of unified understanding, which includes the lubrication mechanism of fibrous tissue in polymers, the evolution mechanism of lubrication film, the interaction effect of internal and external factors on friction performance, and whether friction pairs have obtained 
good tribological properties due to the existence of friction reaction membranes, etc. At present, carbon fiber $(\mathrm{CF})$ and glass fiber (GF) are mainly used to enhance the wear resistance of engineering plastics such as ultra high molecular weight polyethylene (UHMWPE), poly tetra fluoro ethylene (PTFE), polyetheretherketone (PEEK), polyphenylene sulfide (PPS) and ethylene propylene EP. Yamamoto Y. et al. [15] found that the carbon fiber is more suitable than glass fiber as the enhancement phase of PEEK material. In addition, the content of fiber is closely related to the friction and wear properties of composites. The PEEK matrix composites filled with $10 \%$ carbon fiber exhibit optimal tribological properties under seawater lubrication conditions [16]. Moreover, the orientation of the fiber perpendicular to the friction interface in the polymer has better tribological properties.

To sum up, polymer composites have excellent adhesion, mechanical properties, chemical corrosion resistance and other excellent properties, and have good mechanical processing and ductility energy. Therefore, it is an effective means to develop marine equipment to replace some metallic materials with polymer composites in marine equipment. Moreover, further quantitative characterization is still needed to promote the engineering application of polymer materials in the field of marine equipment.

\section{TRIBOLOGICAL BEHAVIOR OF FRICTION PAIR MATERIALS}

\subsection{Metal and metal pairs}

The metal alloys are widely used in petroleum, chemical, biological, navigation and other fields because of their excellent properties, such as high specific strength, high temperature resistance and corrosion resistance. In recent years, with the development and utilization of marine equipment, some alloys have excellent corrosion resistance, good low temperature performance, embedding and compliance performance, provide technical support for the selection of key friction materials in areas such as underwater robots, deep-sea equipment, seawater plunger pump. So the study of tribological properties of metallic materials in the marine environment has attracted much attention. Bhuhsan [17] investigated the tribological characteristics of metal-metal pairs in seawater. The results show that the surface roughness under water lubrication is increased, and the wear amount is reduced to some extent by adding appropriate lubricant into water, but the friction coefficient is more than 0.3. Ding et al. [18] found that the friction pair of $\mathrm{TC} 11$ (titanium alloy)/GCr15 (bearing steel) in artificial seawater has low friction coefficient compared with in pure water. The lubrication surface film formed on the wear scars in the artificial seawater could reduce the friction coefficient. But the wear volume of TC11 in the artificial seawater was always higher than that in the distilled water, which demonstrates that the corrosion of seawater accelerated the wear. The potentiodynamic anodic polarization curves indicated that the passive film was easier to breakdown after wear. The wear mechanism of TC11 in water was only abrasion wear, whereas in seawater, it became delamination fatigue associated with abrasive wear. The 3D topography of the wear scars surface of TC11 titanium alloy is shown in Fig. 1. It can be seen that the straight groove in the seawater medium has regular pits at the bottom, while the bottom in the water medium has irregular jagged shape. The tribological properties of friction pairs of ZChSnSb8-8 (babbitt alloy)/AISI52100 (bearing steel) [19], and TC4/GCr15 [8] were investigated under sea water condition. Through the above research, it can be seen that the tribological behavior of metal and metal pairs in seawater is not only affected by the pressure of seawater and the concentration of halide, but also the comprehensive effect of seawater cooling, lubrication and corrosion on friction pairs. Seawater plays a role in lubrication to some extent, but its corrosion to metallic materials exacerbates its wear and tear. Therefore, the study of the friction and wear mechanism of seawater cooling, lubrication and corrosion on its joint action can better reflect its tribological behavior in seawater.

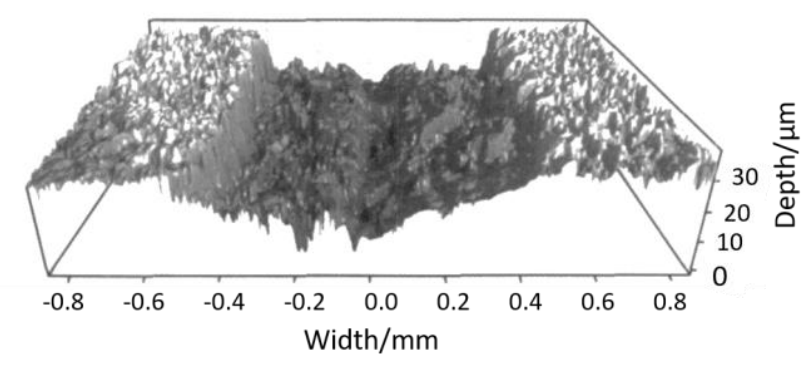

a

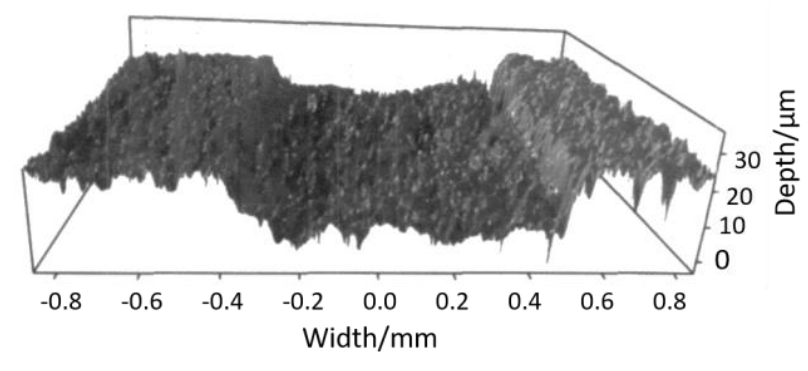

b

Fig. 1. 3D-morphology of wear scars: $a-$ in distilled water; $b$-in sea water [18]

\subsection{Ceramics and metal pairs}

The ceramic materials are widely used in engineering fields because of their corrosion resistance, high temperature resistance, high hardness, wear resistance, pollution-free and other characteristics. With the development of science and technology, the application of new ceramic materials in the field of engineering continues to expand, especially the ocean ceramic materials with the work stably and reliably requirement in extreme environment. The ceramic friction pairs based on seawater lubrication came into being. Zhou et al. [20] investigated the ceramics and metal pairs under water lubrication show that the main wear mechanism of ceramics and metal pairs is adhesive wear, which induces three-body wear. The wear amount is large, the friction coefficient is high and unstable. The water plays no role in lubrication. Under 
seawater lubrication, the maximum pressure velocity (PV) value of ceramics and metal pairs is $20 \mathrm{MPa} \cdot \mathrm{m} / \mathrm{s}$. Liu, et al. [21] study the tribological behaviors of $\mathrm{Si}_{3} \mathrm{~N}_{4}$ ceramic sliding against 316 stainless steel under seawater lubrication compared with those under dry sliding and pure water lubrication. The results showed that $\mathrm{SiO}_{2}$ colloidal particles were formed on the rubbing surface of $\mathrm{Si}_{3} \mathrm{~N}_{4}$ due to the friction-induced chemical reaction of $\mathrm{Si}_{3} \mathrm{~N}_{4}$ with $\mathrm{H}_{2} \mathrm{O}$, which were further aggregated into the silica gel with the assistance of ions in seawater. Because of the boundary lubrication of the silica gel layer, both the lowest friction coefficient and the smallest wear rates of $\mathrm{Si}_{3} \mathrm{~N}_{4}$ and 316 steel were obtained in seawater. In addition, the tribological properties of ceramics and metal pairs of $\mathrm{TC} 4 / \mathrm{Al}_{2} \mathrm{O}_{3}$ [22], $\mathrm{SiC}$ composite ceramic/stainless steel [23], and $\mathrm{Ti}_{3} \mathrm{AlO}_{2}$ ceramics/AISI 316L[24] under seawater lubrication were investigated compared with those under dry sliding or/and pure water lubrication. In general, a lubrication film forms through friction chemical reaction on the friction surface of ceramic materials in the water lubrication environment. This could reduce the friction factor and wear rate. Some ions contained in seawater can promote friction reaction and the formation of lubrication film, so that it has better tribological characteristics. Ceramic friction pairs are mainly affected by the interaction of mechanical wear and friction chemical wear.

\subsection{Polymers and metal pairs}

Polymers and their composites can produce large deformation under certain conditions they have good complete restoration ability relative to metal and ceramic materials. Their embedded abrasive characteristics can greatly improve their wear resistance, so it is widely used in seawater environment of key friction materials. At present, the mechanical parts put forward extremely high performance requirements due to the harsh working environment. The polymer composites not only have good mechanical properties and friction properties, but also have good chemical stability and other advantages, so they become a new choice of seawater lubrication materials. The pairs of polymers and metals are listed in Table 2. Table 3 shows the friction coefficient and wear rate of five materials with GCr15 and Ni-CR-WC respectively in seawater. The friction tests were conducted in the linear velocity of $0.5 \mathrm{~m} / \mathrm{s}$, the load of $100 \mathrm{~N}$, and the test time of $90 \mathrm{~min}$. Before each test, the friction surface was polished to the roughness of about $0.10 \mu \mathrm{m}$ [27].

Table 2. Pairs of polymers and metals

\begin{tabular}{|c|c|}
\hline Authors & Materials \\
\hline Lancaster et al. [25] & $\begin{array}{c}\text { Carbon fibre-reinforced polymers, S80 } \\
\text { stainless steel }\end{array}$ \\
\hline Wang et al. [26] & PTFE/GCr15 \\
\hline Wang et al. [27, 28] & $\begin{array}{c}\text { UHMWPE, PTFE, GCr15 steel, Ni-Cr- } \\
\text { WC alloy, 316 steel, Hastelloy C-216, } \\
\text { Inconel 625, Ti6Al4V alloy }\end{array}$ \\
\hline Sun et al. [29, 30] & $\begin{array}{c}\text { Throdon ceramic bearing/Nickel plated } \\
\text { steel spindle }\end{array}$ \\
\hline Duan et al. [31] & $\begin{array}{c}\text { Throdon ceramic bearing, Tenmat bearing, } \\
\text { UHMWPE, GCr15 }\end{array}$ \\
\hline Zhang et al. [32] & PTFE/ Nickel plated 45\# steel \\
\hline
\end{tabular}

Table 3. The friction coefficient and water rate of polymer [27]

\begin{tabular}{|c|c|c|c|c|}
\hline \multirow{2}{*}{ Materials } & \multicolumn{2}{|c|}{ Friction coefficient } & \multicolumn{2}{c|}{$\begin{array}{c}\text { Wear rate } \\
/\left(10^{-7} \mathrm{~mm}^{3} \cdot \mathrm{N}^{-1} \cdot \mathrm{m}^{-1}\right)\end{array}$} \\
\cline { 2 - 5 } & GCr15 & Ni-Cr-WC & $\mathrm{GCr} 15$ & $\mathrm{Ni}-\mathrm{Cr}-\mathrm{WC}$ \\
\hline UHMWOPE & 0.14 & 0.02 & 32.4 & 5.74 \\
\hline PTFE & 0.05 & 0.02 & 830 & 53.5 \\
\hline PHB /PTFE & 0.10 & 0.02 & 338 & 13.2 \\
\hline Graphite /PTFE & 0.05 & 0.01 & 116 & 6.75 \\
\hline $\begin{array}{c}\text { Carbon fiber } \\
\text { /PTFE }\end{array}$ & 0.12 & 0.04 & 6.66 & 4.17 \\
\hline
\end{tabular}

\subsection{Polymers and ceramics pairs}

Shen et al. [33] investigated polymers and ceramics pairs incuding $\left(\mathrm{Si}_{3} \mathrm{~N}_{4}, \quad \mathrm{SiC}\right) / \mathrm{PEEK}, \quad 316 \mathrm{~L} / \mathrm{PEEK}$, 17-4PH/PEEK, and found that silicon nitride $\left(\mathrm{Si}_{3} \mathrm{~N}_{4}\right)$ is not suitable for friction mating materials whose sliding speed often changes, but is suitable for occasions where pressure keeps changing. In addition, more polymers and ceramics pairs of CF/PEEK [16], PEEK450-FC30/SiC [34], Ti(C, N)-based cermet/ CFRPEEK [35] were studied on the tribological behaviors of their pairs under sea water lubrication.

As one of the core components of seawater hydraulic transmission, seawater hydraulic pump is widely used in marine engineering equipment technology, and the material of key friction pair of seawater hydraulic pump has been greatly restricted because of the special use environment. On the one hand, friction pair materials are needed to resist seawater corrosion. On the other hand, friction pair materials need wear resistance, so it is very important to study the material suitable for the key friction components of seawater hydraulic pump.

In seawater environment, the polymer composites with better mechanical properties and excellent friction and wear characteristics are obtained by changing the composition of polymer materials and introducing glass fiber, carbon fiber and other materials. However, the wear of polymers is still affected by auxiliary materials. The development of nanomaterials technology provides a new theory and method for the study of polymer tribology modification.

A systematic study of the synergy of nano-polymer materials and composite fillers can improve the tribological properties of polymer materials in seawater environment. Metallic ceramics with good wear resistance, high hardness and good chemical stability have the characteristics of both metal and ceramic materials, and is also one of the research hotspots of friction materials in seawater environment in recent years. The excellent tribological properties of combining polymers with some ceramic materials can provide an important basis for the selection of key friction materials in seawater hydraulic pumps.

\subsection{Coating technologies}

Besides the several described friction materials in seawater environment earlier, there are a number new techniques of emerged surface engineering, such as surface coating, surface modification and thin film. For example, the ceramic is sprayed on the surface of metal parts by means of thermal spraying or plasma spraying. The 
ceramic coating technology not only overcomes the brittleness of ceramics, but also maintains the toughness and workability of matrix metallic materials, and makes the surface of parts have strong corrosion resistance and wear resistance [36]. The surface engineering technology has become an important means to realize the final performance of marine engineering equipment material in recent years. It cannot destroy the material's own performance, and strengthen or regenerate the surface properties of the material. So that the surface of the material has excellent tribological characteristics. The surface strengthening technology of key components marine engineering equipment mainly has ion implantation, surface coating technology, etc. Zhang et al. [37] studied the corrosion-resistance and tribological properties of electroless Ni-B coatings on 45 steel. Fig. 2 shows SEM and AFM morphologies of the uncoated and the Ni-B coated 45steel. The Ni-B coating was electrolessly deposited on 45 \# steel to improve its corrosion-resistance and tribological performances. The tribological behavior of $\mathrm{Ni}-\mathrm{B}$ coating on steel was evaluated under lubrication of $3.5 \% \mathrm{NaCl}$ solution. The results show that the electroless Ni-B coating on 45 \# steel possesses a cauliflower-like morphology with amorphous structure. Meanwhile, the Ni-B coating has lower friction and wear scar width than 45 \# steel under lubrication of $3.5 \% \mathrm{NaCl}$ solution.

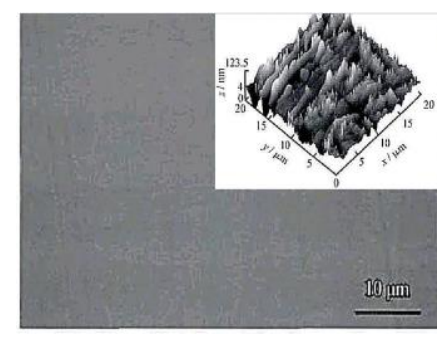

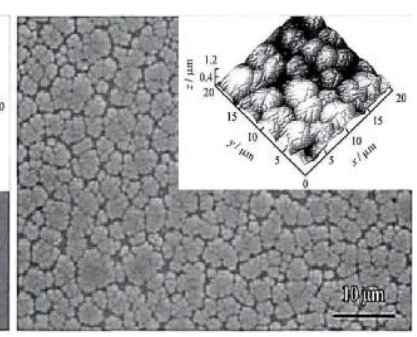

b
Fig. 2. SEM and AFM morphologies of: a - the uncoated 45 steel; $\mathrm{b}-$ the Ni-B coated 45 steel [37]

The corrosion behavior of many friction materials in the marine environment, involves the coupling tribological behavior under electrochemical corrosion, load and corrosion [38, 39]. It is very important to study the corrosion resistance of materials in seawater environment. By selecting materials with excellent performance and optimizing the design of workpieces to reduce corrosion and wear in the friction process, it is also one of the development trends in recent years to control corrosion wear by electrochemical protection and surface treatment. The surface modification of the material such as Grapheneepoxy coatings [40], cast iron with epoxy resin coatings (different epoxy value) [41], Ni-P alloy coating on GCr15 alloys [42-44] can also improve the wear resistance and corrosion resistance of the material, and has been paid more and more attention in the field of material corrosion prevention. It is also very important to reduce the corrosion and wear of materials by studying the electrochemical corrosion of materials and the coupling tribological behavior under the action of load and corrosion. The new research method can greatly widen the species of marine materials, and also provides a strong support for the key friction materials of marine engineering equipment. The exploring of surface technology and corrosion resistance technology for different pairs to obtain excellent tribological properties is the development direction of key friction materials in the future marine environment.

\section{CONCLUSIONS}

In this review, the tribological behavior of materials in seawater environment is discussed, especially emphasis on three kinds of tribological properties of materials: ceramic materials, polymer materials and metallic materials.

1. Ceramic materials in seawater lubrication have a very excellent friction and wear performance. The reaction products of friction chemical can effectively protect and lubricate the friction surface, reduce friction factor and wear rate.

2. Polymer materials have high application value in seawater environment, however the effects of water absorption plasticizing, corrosion of dual parts and surface morphology need to be considered.

3. Metallic materials are inevitably corroded in seawater environment, and the coordination of corrosion and wear has obvious influence on their tribological behavior, among which the quantitative analysis of corrosion and wear has the very important research value.

4. Coating material is an important means to improve the wear resistance and corrosion resistance of matrix materials in seawater environment, depending on the physical and mechanical properties and interfacial properties of coating materials.

\section{PROSPECTS}

The ocean is the basic space for human existence and the treasure house to ensure the sustainable development of human society. The 21 st century is the century of the sea, with the increasingly depleted of land resources, the marine development has been more and more attention. The development of marine engineering equipment needs the support of marine special materials. The friction-wear in seawater environment is one of the key problems restricting the application and popularization of marine materials, mainly due to the complexity of seawater media, as well as the interaction between corrosion and friction. Therefore, it is an important way to study and discuss the tribology of key friction materials in marine environment to improve the overall level of marine engineering equipment. The tribological research on materials in marine environment not only promotes the development of marine engineering equipment, but also provides a strong support for the key friction materials of marine engineering equipment.

The material science, anti-corrosion and other subject contents can make up for the lack of existing knowledge, provide new methods and ideas for the solution of engineering technical problems existing in the marine field, and also provide strong support for the safety and reliability of marine equipment's and key friction pairs. Although there has been some development in material 
tribology of marine environment. The tribological problems in marine engineering equipments are complex and varied due to the complex and changeable marine environment, as well as the difficult test. Hence, there are still many problems to further study in this field. The tribological research on key friction materials under the marine environment can not only enrich the existing tribological theory, but also promote the rapid development of tribology experiments in the extreme environment of the ocean. Study on the friction and wear properties of materials in the marine environment may face the following challenges:

1. The friction and wear of materials in seawater environment are mostly caused by the interaction of many factors. The study of interaction mechanisms on the tribology of materials is not sufficient, such as, the interaction mechanism of corrosion, mechanical wear, and friction chemical wear on key friction pairs. It is very important to perfect the influence mechanism of the interaction on the friction pairs.

2. The seawater medium environment is more complex, and the influence mechanism of seawater environment on material tribology is not perfect, such as, the influence of seawater pressure, halide concentration, sediment content and temperature on the friction performance of key friction pairs.

3. The test methods and techniques need to be further improved. The study of tribological characteristics of key friction materials in marine environment is necessary to associate the test simulation with the actual marine test, and also to associate the designed test device with the actual marine engineering equipment.

4. It is not sufficient that the research on the friction and wear mechanism of key friction pairs in deep sea environment, such as, the tribological properties of key components friction pairs under the interaction of high pressure and large loads in seawater environment.

5. The reliability and life of key friction materials in the marine environment is the premise to ensure the safe and reliable operation of marine engineering equipment. The establishment of key test technology and database of friction materials lays a foundation for improving the working performance of the materials.

\section{Acknowledgments}

This word was supported by the National Key R\&D Program of China (2019YFC0408404, 2017YFC0404200), Shandong Province Key R\&D Program (2019TSLH0304), Tianjin Science and Technology Planning Project (18YFZCSF00310) and Special fund for basic scientific research business of central public research institutes (KJBYWF-2019-ZD01).

\section{REFERENCES}

1. Xu, L.P., Mao, J., Zhang, J.F., Deng, C.G., Liu, M., Zhou, K.S. Applications of Surface Engineering Technology in Marine Engineering Equipment Materials China 33 (1) 2014: pp. 1-8. (in Chinese) https://doi.org/10.7502/j.issn.1674-3962.2014.01.01

2. Wen, H.X., Sun, J.J., Chen, W. Tribological Study of the Key Friction Pairs Materials under Seawater: Research
Status and Prospects Materials Review

2016: pp. $85-91$.

https://doi.org/10.11896/j.issn.1005-023X.2016.015.014

3. Chen, J., Li, Q.A., Zhang, Q., Song, L.F., Chen, X.Y. Effect of Corrosion on Wear Resistance of Several Metals in Seawater Transactions of Materials and Heat Treatment 35 (12) 2014: pp. 166-171. (in Chinese) https://doi.org/10.13289/j.issn.1009-6264.2014.12.030

4. Xu, F.Y. Analysis of Anticorrosion for Equipments in Chemical Industry Leather Chemicals 24 (1) 2007: pp. $41-44$.

https://doi.org/10.1103/PhysRevE.75.061406

5. Wang, J.Z., Chen, J., Chen, B.B., Yan, F.Y., Xue, Q.J. Wear Behaviors and Wear Mechanisms of Several Alloys under Simulated Deep-sea Environment Covering Seawater Hydrostatic Pressure Tribology International 56 2012: pp. $38-46$.

https://doi.org/10.1016/j.triboint.2012.06.021

6. Zhang, Y., Yin, X.Y., Yan, F.Y. Effect of Halide Concentration on Tribocorrosion Behavior of 304SS in Artificial Seawater 99 Corrosion Science 2015: pp. $272-280$.

https://doi.org/10.1016/j.corsci.2015.07.017

7. Cui, G.J., Bi, Q.L., Zhu, S.Y., Yang, J., Liu, W.M. Tribological Behavior of Cu-6Sn-6 Zn-3Pb under Sea Water, Distilled Water and Dry-sliding Conditions Tribology International 55 2012: pp. 126-134.

https://doi.org/10.1016/j.triboint.2012.06.007

8. Zhu, S.Y., Bi, Q.L., Yang, J., Qiao, Z.H, Ma, J.Q., Li, F., Yin, B., Liu, W.M. Tribological Behavior of $\mathrm{Ni}_{3} \mathrm{Al}$ Alloy at Dry Friction and under Seawater Environment Tribology International 75 2014: pp. 24-30.

https://doi.org/10.1016/j.triboint.2014.03.006

9. Ren, S.F., Meng, J.H., Lu, J.J., Yang, S.R. Tribological Properties of Ti3SiC2, Stainless Steel and NiCr Alloy in Artificial Seawater Tribology 33 (4) 2013: pp. 363-371. (in Chinese).

https://doi.org/10.16078/j.tribology.2013.04.006

10. Wang, W., Wen, H.X., Chen, W. Research Status on Tribological Behaviors of Materials under Seawater Environment Materials Review 31 (11) 2017: pp. 51 - 58. (in Chinese).

https://doi.org/10.11896/j.issn.1005-023X.2017.011.007

11. Chen, M., Kato, K., Adachi, K. The Difference in Running-in Period and Friction Coefficient between Selfmated $\mathrm{Si}_{3} \mathrm{~N}_{4}$ and $\mathrm{SiC}$ Sliding in Water Tribology Letters 11 (1) 2001: pp. 23-28. https://doi.org/10.1023/A:1016621929078

12. Gates, R.S., Hsu, S.M. Tribochemistry between Water and $\mathrm{Si}_{3} \mathrm{~N}_{4}$ and $\mathrm{SiC}$ : Induction Time Analysis Tribology Letters 17 (3) 2004: pp. 399-407.

https://doi.org/10.1023/B:TRIL.0000044488.84437.68

13. Yu, X.Y., Zhang, O.H., Luo, S.C. Experimental Study of Ceramic Bearings Lubricated by Water Lubrication Engineering 3 1994: pp. 49-51. (in Chinese).

14. Chen, W., Liu, X., Wen, H.X. Tribology and Prospect of PEEK Composites in Marine Environment Engineering Plastics Application 45 (08) 2017: pp. 135-138. (in Chinese). https://doi.org/10.3969/j.issn.1001-3539.2017.08.028

15. Yamamoto, Y., Hashimoto, M. Friction and Wear of Water Lubricated PEEK and PPS Sliding Contacts Wear 253 (7-8) 2002: pp. 820-826. https://doi.org/10.1016/S0043-1648(02)00059-5

16. Chen, B.B., Wang, J.Z., Yan, F.Y. Comparative Investigation on the Tribological Behaviors of CF/PEEK Composites under Sea Water Lubrication Tribology International 52 2012: pp.170-177. 
https://doi.org/10.1016/j.triboint.2012.03.017

17. Bhushan, B., Gray, S. Investigation of Material Combinations under High Load and Speed in Synthetic Seawater Lubrication Engineering 35 (11) 1979: pp. 628-639.

18. Ding, H.Y., Dai, Z.D. Corrosion Wear Characteristic of TC11 Alloy in Artificial Sea Water Tribology 28 (2) 2008: pp. 139-144. (in Chinese). https://doi.org/10.3321/j.issn:1004-0595.2008.02.009

19. Wu, H.R., Bi, Q.L., Yang, J., Liu, W.M. Tribological Performance of Tinbased White Metal ZChSnSb8-8 under Simulated Sea Water Environment Tribology 31 (3) 2011: pp. 271 - 277. (in Chinese). https://doi.org/10.1080/17415993.2010.547197

20. Zhou, H., Jiao, S.J., Li, J.X. Material Selection of Friction Pairs for Water Hydraulic Piston Pump Chinese Hydraulics \& Pneumatics (7) 2002: pp. 40-41. (in Chinese).

https://doi.org/10.3969/j.issn.1000-4858.2002.07.019

21. Liu, N., Wang, J.Z., Chen, B.B., Yan, F.Y. Tribochemical Aspects of Silicon Nitride Ceramic Sliding against Stainless Steel under the Lubrication of Seawater Tribology International 61 2013: pp. 205-213. https://doi.org/10.1016/j.triboint.2013.01.011

22. Chen, J., Yan, F.Y., Wang, J.Z. Corrosion Wear Properties of TC4 Titanium Alloy in Artificial Seawater Tribology 32 (1) 2012: pp. 1-6. (in Chinese).

https://doi.org/10.16078/j.tribology.2012.01.005

23. Cui, G.J., Bi, Q.L., Niu, M.Y., Yang, J., Liu, W.M. The Tribological Properties of Bronze-SiC-graphite Composites under Seawater Condition Tribology International 60 2013: pp. $25-35$.

https://doi.org/10.1016/j.triboint.2012.11.005

24. Wang, S., Cheng, J., Zhu, S.Y., Qiao, Z.H., Yang, J., Liu, W.M. Frictional properties of $\mathrm{Ti}_{3} \mathrm{AlC}_{2}$ Ceramic against Different Counterparts in Deionized Water and Artificial Seawater Ceram International 42 2016: pp. 4578-4585. https://doi.org/10.1016/j.ceramint.2015.11.153

25. Lancaster, J.K. Lubrication of Carbon Fiber-reinforced Polymers Part 1 -Water and Aqueous Solutions Wear 20 1972: pp. 315-333. https://doi.org/10.1016/0043-1648(72)90413-9

26. Wang, J.Z., Yan, F.Y., Xue, Q.J. Tribological Behavior of PTFE in Seawater Proceedings of the 25th Annual Meeting of Gansu Chemical Society, Lanzhou, 2007: pp. $183-186$.

27. Wang, J.Z., Yan, F.Y., Xue, Q.J. Tribological Behaviors of Some Polymeric Materials in Sea Water Chinese Science Bulletin 54 (22) 2009: pp. 3358-3564. https://doi.org/10.1007/s11434-009-0578-4

28. Wang, J.Z. Research of Tribological Properties of Materials under Seawater. Beijing: University of Chinese Academy of Sciences, 2010. (in Chinese)

29. Sun, W.L. Experimental Study on the Seawater Mechanism and Lubrication Analysis of Seawater Lubrication Thordon Bearings. Qingdao: Qingdao Technological University, 2010. (in Chinese).

30. Sun, W.L., Wang, Y.Q., Shi, G.W. Wear Mechanism Analysis of Seawater Lubrication Thordon Lubrication Engineering 36 (7) 2011: pp. 48 -51. (in Chinese) https://doi.org/10.3969/j.issn.0254-0150.2011.07.012

31. Duan, H.T. Numerical Simulation of Water Lubricated Bearing and Study on Materials Tribological Properties. Beijing: China Academy of Machinery Science and Technology, 2011. (in Chinese)
32. Zhang, L.J. The Study on Tribology Characteristics of Seawater Lubrication Plastic Bearings. Qingdao: Qingdao Technological University, 2012. (in Chinese)

33. Shen, F.M. Material Matching Properity and Reliability Research of Key Friction Pairs in the Sea Water Hydraulic Piston Pump. Beijing: Beijing University of Technology, 2014. (in Chinese)

34. Liao, W.J., Nie, S.L., Li, L., Zhang, Z.H., Yuan, S.H. Tribological Behavior of Carbon Fiber-Reinforced PEEK Sliding against Engineering Ceramic Sic Lubricated with Seawater Chinese Hydraulics Pneumatics 2015: pp. 16-19. (in Chinese). https://doi.org/10.11832/j.issn.1000-4858.2015.08.003

35. Tang, Q.G., Chen, J.T., Jin, W.H., He, X.F. Study on the Tribological Behaviors of $\mathrm{Ti}(\mathrm{C}, \mathrm{N})$ Cermet Lubricated with Seawater Lubrication Engineering 36 (1) 2011: pp. 1-3. (in Chinese). https://doi.org/10.1080/17415993.2010.547197

36. Wahab, J.A., Ghazali, M.J., Ahmad, F.S.B. Microstructure and mechanical properties of plasma sprayed $\mathrm{Al}_{2} \mathrm{O}_{3}-13 \% \quad \mathrm{TiO}_{2}$ Ceramic Coating MATEC Web of Conferences 87 2017: pp. 02027. https://doi.org/10.1051/matecconf/20178702027

37. Zhang, M.X., Cao, L., Wang, Y.Y., Wan, Y. Corrosionresistance and Tribological Properties of Electroless Ni-B Coatings on 45steel China Surface Engineering 28 (3) 2015: pp. 63-69. (in Chinese). https://doi.org/10.11933/j.issn.1007-9289.2015.03.010

38. Li, Y., Qu, L., Wang, F.H. The Electrochemical Corrosion Behavior of $\mathrm{TiN}$ and (Ti, $\mathrm{Al}) \mathrm{N}$ Coatings in Acid and Salt Solution Corrosion Science 45 (7) 2003: pp. $1367-1381$ https://doi.org/10.1016/S0010-938X(02)00223-8

39. Nikita, Z., Manas, M., Andrew, D., Peng, Y., Li, L.J., Zhou, A.H. Corrosion Resistance of Pulsed Laser-treated Ti-6Al-4V Implant in Simulated Biofluids Electrochim Acta 53 (15) 2008: pp. 5022-5032. https://doi.org/10.1016/j.electacta.2008.01.086

40. Liu, S., Jiang, X., Zhao, H.C., Gu, L., Wang, Y.X., Li, J.L., Yu, H.B., Chen, J.M. Corrosion Resistance and Wear Property of Graphene-epoxy Coatings Tribology 35 (5) 2015: pp. 598-605. (in Chinese). https://doi.org/10.16078/j.tribology.2015.05.012

41. Chen, H., Wu, F., Zhao, W.J., Zeng, Z.X., Wu, X.D., Xue, Q.J. Influence of Epoxy Value on the Tribological Performances of Epoxy Resin Coatings in Seawater Environment Tribology 34 (6) 2014: pp. 601-607. (in Chinese). https://doi.org/10.16078/j.tribology.2014.06.001

42. Wang, J.Z., Chen, B.B, Yan, F.Y. Influence of Seawater Constituents on the Lubrication Effect of Seawater Lubrication Engineering 36 (11) 2011: pp. 1-5. (in Chinese). https://doi.org/10.1002/clc.20818

43. Wang, J.Z., Yan, F.Y., Xue, Q.J. Friction and Wear Behavior of Ultrahigh Molecular Weight Polyethylene Sliding Against GCr15steel and Electroless Ni-P Alloy Coating under the Lubrication of Seawater Tribology Letters 35 2009: pp. 85-95. https://doi.org/10.1007/s11249-009-9435-5

44. Wang, J.Z., Yan, F.Y., Xue, Q.J. Tribological Behavior of PTFE Sliding Against Steel in Sea Water Wear 267 2009: pp. $1634-1641$

https://doi.org/10.1016/j.wear.2009.06.015 